\title{
State Analysis of Underground Self-walking Excavator
}

\author{
Honghu WEI \\ College of Architecture and Civil Engineering \\ Beijing University of Technology \\ Beijing, China \\ e-mail: baoy@bjut.edu.cn
}

\author{
Yan BAO \\ College of Architecture and Civil Engineering \\ Beijing University of Technology \\ Beijing, China \\ e-mail:Whh888@bjut.edu.cn
}

\author{
Hongwei MA \\ College of Architecture and Civil Engineering \\ Beijing University of Technology \\ Beijing, China \\ e-mail: Wayne@bjut.edu.cn
}

\begin{abstract}
According to designed parameters of self walking excavator, including the radius difference between the head and end of a section, the length of a section of the excavator, and the radius and width of the designed construction circular curve. The relationship is established between above parameters and the deviation of the section edge from the border of the designed hole. Based on general designed parameters of the excavator, various influence factors is analyzed to arrive the effect of different parameters on deviation, the major influence factors. The results will provide the basis for the design of the excavator and engineering construction of underground self walking excavator.
\end{abstract}

Keywords-underground self walking excavator; designed curve; radius difference; hole width; section length; deviation

\section{INTRODUCTION}

With the development of municipal engineering, small diameter pipeline excavation construction is needed for a lot of underground engineering. At present small diameter pipes are constructed mainly with pipe jacking technology. Complexity of the underground environment causes much trouble for pipe jacking construction, such as equipment maintenance and problem solution in processing and so on. With the development of science and technology, the research of underground self walking tunneling technology [1] meets the needs of small diameter engineering construction. At present prototype of the excavator has been completed. That lays a solid foundation for innovating of underground small diameter self walking construction.

The power of driving the excavator is the friction force generated between the slices of increasing insistence mounted on the outside of the excavator and the surrounding soil. Therefore the interaction effect between the slices and the surrounding soil is the key factor for excavator propulsion. Favorable contact between the outer wall of the excavator and the surrounding soil is to provide a sound environment for propulsion.

But the excavator is composed of multisections, and after the passing of formal section, the reverse thrust produced by the second section will be reduced due to the first section's disturbance. In order to ensure enough reverse thrust, the radius of the same section will be gradually increased from the head to the end when designing, and the length of the latter section is longer than the former section.

On the other hand increasing length of the section will hinder the propulsion of the excavator. As a rigid body, When the excavator goes along a curve, the end edge of the section will leave the curve hole and enter the surrounding soil(namely Deviation) and extrudes the lateral soil[2]. the extrusion forms another resistance to the excavator's moving ahead. Smaller curve radius produces stronger extruding resistance. The extrusion results that the hole through the excavating process is not round as designed curve in theory. In order to correct the deformation shield machine is usually designed to have a set of copying knife to overbreak in part [3]. But for self-walking excavator, overbreaking in part will reduce the friction between increasing resistance slices and surrounding soil, and therefore will affect the reverse thrust of the machine.

It is necessary for the designing of the excavator to be clear about the change of deviation under different machine geometry parameters and curve radius and ensuring the regular excavating of the machine. In this paper, according to the designed parameters (section length, radius difference of the head and the end of the section, designed curve radius and designed hole width), the relationship between the deviation and the parameters is established and then is used to calculate deviation under different parameters. The data illustrates that when the designed curve radius is larger than $60 \mathrm{~m}$ deviation is affected by radius difference of the section mainly. When radius difference, hole width, section length and curve radius are $0.20 \mathrm{~m}, 1.2 \mathrm{~m}, 2.6 \mathrm{~m}$ and $5 \mathrm{~m}$ respectively, deviation will be $0.33 \mathrm{~m}$. The results are useful for parameter design of self walking excavator and they provide application condition analys is of the excavator.

\section{PlANE ATTITUDE EXPRESSION OF EXCAVATOR}

The horizontal status of one section of self walking 
excavator is shown in figure 1. The length of the section is $L$, the outer radius of the head and the end of the section is $r_{X}$ and $r_{D}$ respectively, the radius and the width of the designed curve is $R$ and $d$. And assume that the midpoint of the axle of each section inscribes the axle of designed circular curve. Suppose the tangent line at the midpoint of the axle is $X$ axis and $Y$ axis is perpendicular to axle wire of the curve line and goes through the circular center (suppose the center is at point $\mathrm{O}$ ). Based on $r_{X}, r_{D}$ and $L$, the inclination $\gamma$ of the outline of the section is expressed as follow

$$
\gamma=\operatorname{atn}\left(\frac{r_{D}-r_{X}}{L}\right)=\operatorname{atn}\left(\frac{\Delta r}{L}\right)
$$

Among: $\Delta r$ is radius difference between the radius of the head and the end of the section. Because the diameter of the hole depends on the diameter of the first section initially, the deviation can be derived according to excavator geometrical parameters and the radius of the designed circular curve as follow:

$$
\begin{gathered}
B C=\operatorname{Ltg} \gamma \\
O C=R+d / 2+B C \\
O D=\sqrt{O C^{*} O C+C D^{*} C D}
\end{gathered}
$$

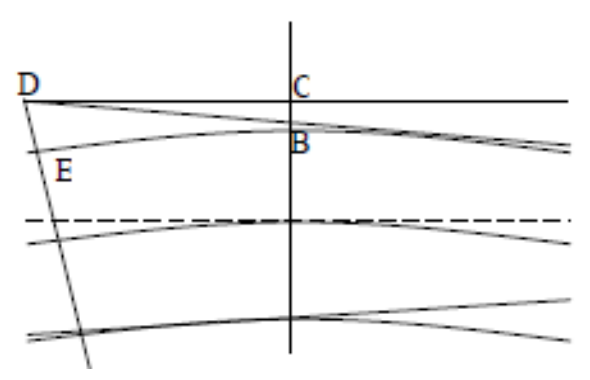

Figure 1. State of self walking tunellor

Where $O$ is the center of circu lar curve. And the deviation $D E$ of the section end is

$$
D E=O D-O E=O D-(R+d / 2)
$$

Apply formula (1), (2), (3) to formula (5) and then it can be arrived.

$$
D E=\sqrt{(R+d / 2+L \operatorname{tg} \gamma)^{2}+(L / 2)^{2}}-(R+d / 2)
$$

\section{ANALYSIS OF IMPACT FACTORS ON DEVIATION}

Figures (2), (3) and (4) are the results calculated in formula (6).

\section{A. Influence of Circular Curve Radius on Deviation}

Figure 2 shows the relationship between deviation and curve radius under different radius difference and same hole width. Figure 2(a) and 2(b) respond to radius difference of $0.10 \mathrm{~m} 0.30 \mathrm{~m}$ respectively.

It can be seen from figure 2 that deviation increases with the increase of curve radius. When curve radius is larger than $60 \mathrm{~m}$, whatever radius difference and section length are deviation is gradually close to radius difference. It shows that when curve radius is larger than $60 \mathrm{~m}$, the hole width and section length affect deviation little and in this case deviation depends mainly on radius difference.

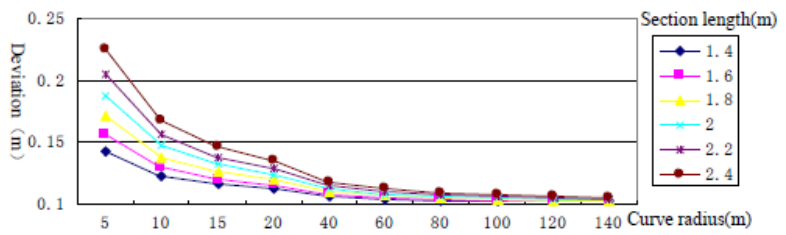

(a) Hole width $1.2 \mathrm{~m}$ radius difference $0.1 \mathrm{~m}$

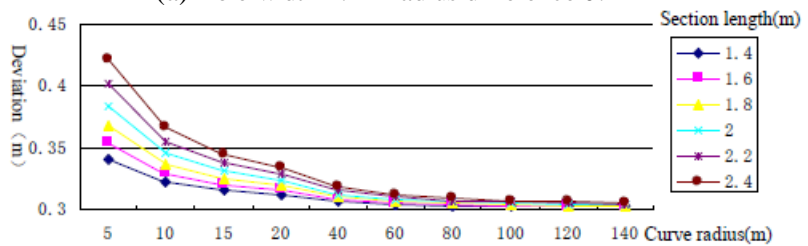

(b) Hole width $1.2 \mathrm{~m}$ radius difference $0.3 \mathrm{~m}$

Figure. 2 Relation bet ween deviation and curve radius

When the curve radius is less than $60 \mathrm{~m}$, the deviation decreases gradually with the decrease of curve radius, and the longer the length is, the larger the deviation increases as shows in figure 2(a) and 2(b). For example when the hole width is $1.2 \mathrm{~m}$ and the section length is from $1.4 \mathrm{~m}$ to $2.6 \mathrm{~m}$, the deviation increases only $3 \mathrm{~cm}$ at the curve radius of $20 \mathrm{~m}$, but when the curve radius decreases to $5 \mathrm{~m}$ in the same section length, deviation increases about $10 \mathrm{~cm}$. This can be seen from figure 2(b). It shows that only when the curve radius is less than $40 \mathrm{~m}$, deviation is affected obviously with the decrease of curve radius.

\section{B. Influence of Section Length on Deviation}

The relationship is shown in figure 3 between deviation and section length under same hole width $(1.2 \mathrm{~m})$, different radius difference $(0.1 \mathrm{~m}$ in figure $3(\mathrm{a}), 0.3 \mathrm{~m}$ in figure $3(\mathrm{~b}))$ and different curve radius. Hole width is $1.2 \mathrm{~m}$, and section lengths are from $1.4 \mathrm{~m}$ to $2.6 \mathrm{~m}$. Generally deviation increases with the increase of section length, but when circular curve radius is larger than $60 \mathrm{~m}$, deviation increase very few with the increase of section length no matter the radius difference of the section is $0.1 \mathrm{~m}$ (figure $3(\mathrm{a})$ ) or $0.3 \mathrm{~m}$ (figure 3(b)). When the curve radius decreases to $5 \mathrm{~m}$, deviation increases rapidly with the section length increasing. When the curve radius increases, deviation increases slowly with the increase of section length. For example when the curve radius increases to $60 \mathrm{~m}$, the deviation is basically independently to the section length. 
Comparis on of figure 3(a) and 3(b) illustrates that under the condition of same curve radius and section length the deviation difference corresponding different section radius difference is equal to section radius difference.

When the curve radius is $5 \mathrm{~m}$ and the section length is $1.4 \mathrm{~m}$, the deviation is $0.14 \mathrm{~m}$ and $0.34 \mathrm{~m}$ corresponding to the section radius differences of $0.1 \mathrm{~m}$ and $0.3 \mathrm{~m}$ respectively. This illustrates that the deviation difference corresponding to different section radius is just equal to the section radius difference. When the section length increases to $2.6 \mathrm{~m}$, the deviation difference corresponding to different section radius is still equal to the section radius difference. That means the deviation resulting from the section length is under the control of section radius difference.

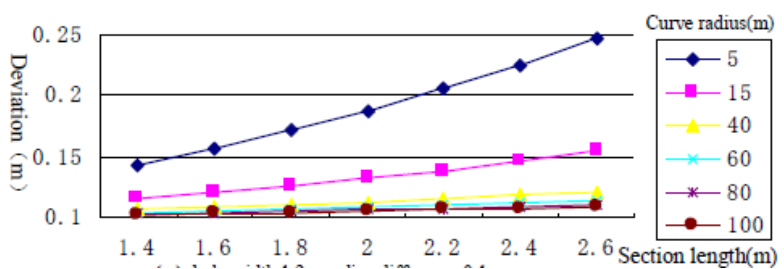

(a) Hole width $1.2 \mathrm{~m}$ radius difference $0.1 \mathrm{~m}$

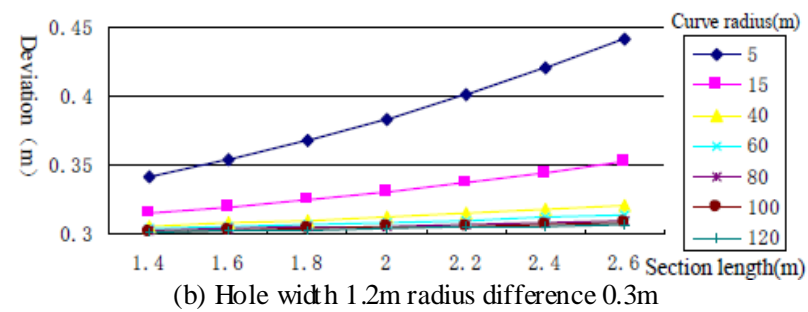

Figure 3. Relation between deviation and section length

\section{Influence of Hole Width on Deviation}

The effect of hole width on deviation is shown in figure 4. Figure 4(a) and 4(b) respond to radius difference of $0.1 \mathrm{~m}$ and $0.3 \mathrm{~m}$ respectively. Comparis on of figure $4(\mathrm{a})$ and $4(\mathrm{~b})$ shows that deviation in two figures is almost the same in shape. When curve radius decreases to $5 \mathrm{~m}$ and hole width changes from $1.2 \mathrm{~m}$ to $2.0 \mathrm{~m}$, the deviation decreases just only $1 \mathrm{~cm}$ no matter what the curve radius is $0.1 \mathrm{~m}$ or $0.3 \mathrm{~m}$. That shows hole width does not affect the deviation mainly.

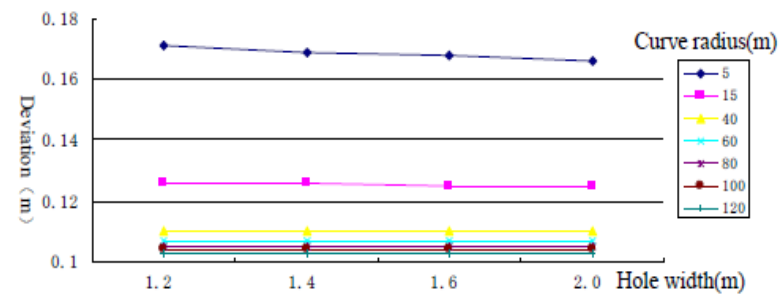

(a) Section length $2.0 \mathrm{~m}$ radius difference $0.1 \mathrm{~m}$

Figure 4. Relation between deviation and hole width

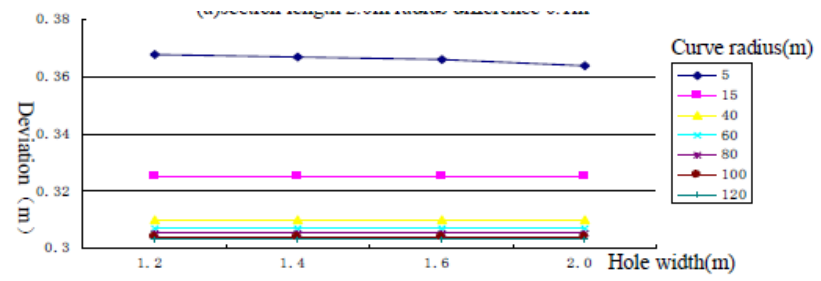

(b) Section length $2.0 \mathrm{~m}$ radius difference $0.3 \mathrm{~m}$

Figure 4. Relation between deviation and hole width

\section{CONCLUSION}

Based on the above analysis, it can be achieved that radius difference is the most important factor to affect deviation. And section length is the next factor. Hole width influences the deviation little. When the curve radius is larger than $60 \mathrm{~m}$, the deviation is affected mainly by curve radius difference. When the curve radius is less than $60 \mathrm{~m}$, deviation increases gradually with the decrease of the curve radius. The rate of increase is related to the section length. A larger section length will cause a rapid increase of deviation. When radius difference, hole width and curve radius are $0.20 \mathrm{~m}, 1.2 \mathrm{~m}$ and $5 \mathrm{~m}$ respectively, deviation will be $0.24 \mathrm{~m}$ $-0.33 \mathrm{~m}$ corresponding to section length of $1.4 \mathrm{~m}-2.6 \mathrm{~m}$. On this occasion the extrusion of the excavator to the lateral soil can form larger reaction and friction forces; this will cause the excavator deflecting from the designed curve. And furthermore the friction resistance may prevent the tube body moving on.

In summary underground self walking excavator should be designed in section radius difference not larger than $20 \mathrm{~cm}$, and the excavator should not be used in the condition of radius curve less than $5 \mathrm{~m}$.

\section{REFERENCES}

[1] The $12^{\text {th }}$ five-year plan science and technology support project. "Research and development of municipal administration tunnel (pipe) self walking construction technique and equipment", Project number: 2006BAJ16B06.

[2] http://www.doc88.com/p-692279616731.html

[3] Zhang Ying, Li Youjun, He Xiaojian. New technique for tunnel design and construction of minor radius curve. Metropolis fast track transport at ion, 23(5): 75-7. 